\title{
New Radiation Hodoscope Developments for Arms Control Treaty Verification ${ }^{1}$
}

\author{
C. E. Dickerman, R. C. Doerner, J. P. Regis, E. A. Rhodes, \\ G. S. Stanford, D. J. Travis, and A. DeVolpi.
}

ANL/CP- 74511

DE92 003391

Argonne National Laboratory, 9700 S. Cass Ave., Argonne, IL 60439

\section{Abstract}

New developments in hodoscope radiation detection technology offer a wide range of unique capabilities for arms control treaty verification (ACTV) applications. Originally developed for civilian nuclear power research by Argonne National Laboratory, this concept uses an array of radiation detectors to image or detect objects inside opaque containments. Hodoscope systems may detect neutrons and/or gamma-rays. The systems may be based on transmission of radiation through the objects; may detect radiation stimulated in the objects, or may detect intrinsic object radiation. ACTV hodoscopes do not require the high-speed data acquisition systems or the heavy shielding and collimation of reactor hodoscopes, and relatively weak radiation sources are sufficient. We have performed laboratory measurements to demonstrate a range of potential applications. Gamma-ray transmission hodoscopes can be used to inspect canisters, rail cars, etc. to monitor objects such as rocket motors. The use of relatively weak radiation sources makes it unnecessary to employ expensive and high-intensity accelerators. The heavy metal of nuclear warheads is characterized by strong gamma-ray absorption, and these materials could be counted by low-resolution tomography. Absorbers located in line with objects will themselves be detected, and sources located in the object region will be subtracted out as background. Intrinsic gamma-ray radiation from warheads also can be detected in a passive-instrument mode. Neutron hodoscopes can utilize neutron transmission, intrinsic neutron emission, or neutron-producing reactions (either prompt or delayed) stimulated by a neutron source. Monitoring of rocket motors enclosed in canisters/rail cars is the focus of the most recent ACTV hodoscope research and development activities.

\footnotetext{
1 Angonne National Laboratory is owned by the U.S. govemment, and operated by the University of Chicago under the provisions of a contract with the Department of Energy. This work was performed under sponsorship of the U.S. Department of Energy Office of Arms Control as part of a research and development program and does not imply current or future policy decisions or technical preferences of any agency of the U.S. government.
}

\section{INTRODUCTION}

Hodoscope radiation-detection imaging technology was developed for civilian nuclear power research by Argonne National Laboratory for the U.S. Department of Energy TREAT facility[1] and later by a French-German collaboration for the French CABRI facility[2]. This concept uses an array of radiation detectors to image or detect objects and detect their movements inside opaque containments. Detector size and spacing (as well as collimator design, where collimators are used) determine resolution. Reactor hodoscope systems usually are operated to detect neutrons and/ or gamma-rays resulting from nuclear reactions induced by the reactor neutron flux. However, hodoscope systems also may be used to detect transmission of radiation through the region of interest, or may detect intrinsic radiation froni the objects under study. Reactor hodoscope image frames may be recorded at intervals as short as the millisecond range. Because of the high radiation background inherent in the nuclear reactor applications, extensive shielding is required, and heavy collimation is necessary in front of the detectors.

Neutrons or gamma-rays can be used for ACTV applications also. Detector size and spacing fix the resolution of a hodoscope, and are readily determined visually at an ACTV inspection point. The mode of operation could rely upon transmission of radiation, detection of induced radiation (for example, fission neutrons or gamin-rays induced in fissile warhead material by neutron activation), or detection of intrinsic radiation. Because typical ACTV applications do not require cine-type imaging, special high-speed data acquisition systems are not used. Counting times in the range of a minute are generally acceptable. In fact, the typical ACTV requirement that the inspection technique not reveal unacceptable design details to the inspector, makes it desirable to use relatively low counting rates in order to obtain counting statistics that are just sufficient to perform the inspection function required. The relatively high radiation background of a nuclear reactor core is, of course, ausent; we have been able to eliminate shielding and collimation completely in most cases we have siudied.

We have performed proof-of-principle laboratcry measurements to demonstrate application of hodoscope technology to a range of potential appucations including warhead counting, discrimination of nuclear warheads, and monitoring 
of rocket motors enclosed in their canisters. This last demonstration is the focus of the most recent work, which vill be described here.

\section{ROCKET MOTOR MONITORING APPROACH}

Rocket motor monitoring, or discrimination, requires that the inspection determine that the size of a specific enclosed rocket motor is within agreed-upon limits. This requires limited intrusiveness: i.e., there should be an acceptably small impact on facility operations, and the inspection technique should not reveal unacceptable design details. For this application, we chose the gamma-ray transmission hodoscope.

Figure 1 is an illustration of the cross section for this application. This figure shows a highly absorbing rocket motor located inside a canister within a rail car. For simplicity, the source is shown in a fan-beam geometry, and there are two strings of detectors, one to detect the location of the "top edge" of the rocket motor and one to detect the bottom edge. (This layout is based on the existing portal monitoring facility at Votkinsk, which uses a nondestructive radiation imaging system based on a high-power linear accelerator and special data processing equipment.) Previous physics measurements at ANL on laboratory mockups confirmed that collimation was not necessary.

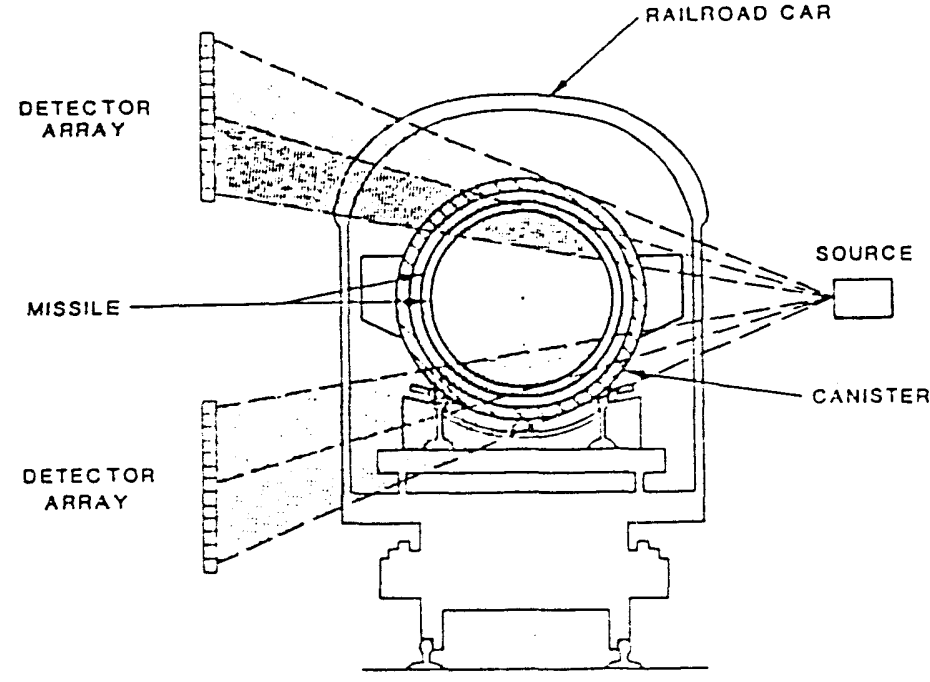

Fig. 1 Rocket motor monitoring schematic

Figure 2 illustrates the approach to monitoring rocket motor size. The top portion shows the motor region of interest. The axial region is excluded, as shown in Fig. 1, because of concern that radiation imaging might reveal unacceptable internal details of the motor design. Similarly, the inter-stage features (including nozzles) also is excluded to protect design information. Next, the agreed-upon measurement parameters are located. Even if the full extent of the acceptable region is imaged, the actual treaty measurement is taken at well defined locations: in the middle part of Fig. 2 , we show examples of diameter and length measurement locations. For hodoscope measurements, it is necessary merely to locate linear strings of detectors at the measurements locations shown in the middle of this figure. These strings are indicated in the bottom sketch of Fig. 2.

\section{PRINCIPLE OF OPERATION}
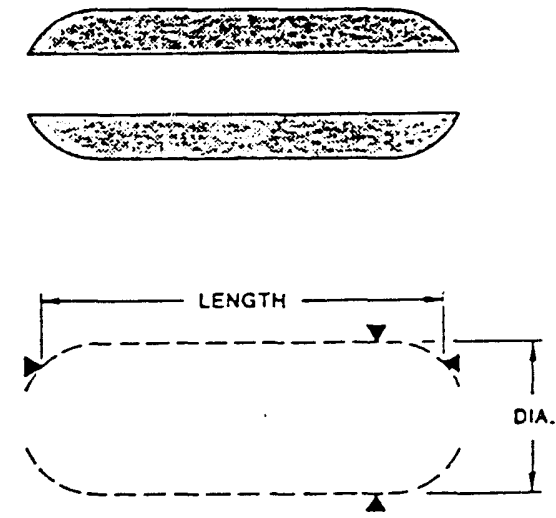

WTH CONVENTIONAL RADIOGRAPHY. OPERATOR MEASURES POINTS ON RADIOGRAPH

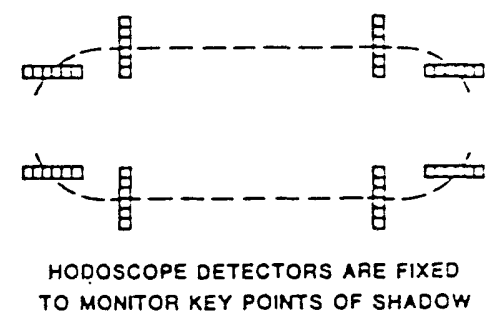

Fig. 2 Hodoscope application to rocket motor monitoring

Location of each edge is determined by obtaining the value of gamma-ray transmission, $\mathrm{T}$, for each detector, using the equation

$$
\mathrm{T}=(\mathrm{D}-\mathrm{C}) /(\mathrm{B}-\mathrm{A})
$$

where $\mathrm{A}=$ background counting rate, object absent; $\mathrm{B}=$ counting rate with source open, object absent; $\mathrm{C}=$ background counting rate, object present; and $\mathrm{D}=$ counting rate with source open, object present. Note that this procedure compensates automatically for the possible presence of radioactive sources inside the object being inspected. Also, referring back to Fig 1, it is apparent that objects placed in the inspection region will cast their gamma-ray shadows on the detector strings. Thus, any attempt to cloak the detection of the edge of an object by introduction of an absorber would be seen (as a larger object). This characteristic, of course applies to the general process of transmission radiography; and it applies to the current Votkinsk installation, as well. 


\section{DEMONSTRATION MEASUREMENTS}

\section{A. Experimental Apparatus}

A laboratory gamma-ray transmission hodoscope was assembled using commercially available components: $\mathrm{NaI}$ detectors, power supplies, amplifiers, pulse-height analyzers, and discriminators. A portable personal computer was used for system operation, and also for data acquisition, processing and display/printout. Scoping calculations indicated that a 20 milliCurie $\mathrm{Co}^{60}$ source would be adequate to determine the edges of a rocket motor, when viewed through representative structure. The use of this source was reviewed to confirm that the measurements were well within As Low As Reasonable Achievable (ALARA) guidelines[3]. At a nominal radiography position, about 2.5 meters from the source, the dose rate is about $2 \mathrm{mR} / \mathrm{hr}$. The Department of Energy ALARA guidelines of Rev. 3 give annual limits for external gamma-ray exposure of 5 Rem R for Occupational Workers, and $100 \mathrm{mR}$ for the general Public. Table I gives the ALARA exposure times corresponding to these annual limits for a person located at the center of the radiography position (2,500 hours and 50 hours, respectively).

Table I

Hodoscope exposure times at radiography position required to reach DOE ALARA yearly exposure guideline limits

\begin{tabular}{cc}
\hline \multicolumn{1}{c}{ Category } & Hours of exposure \\
\cline { 2 - 2 } Occupational Worker & 2,500 \\
General Public & 50 \\
\hline
\end{tabular}

(For reference, the dose rates at the radiography position in the current Votkinsk installation using a linear accelerator are many orders of magnitude higher than the hodoscope dese rates: a person standing in the Votkinsk radiography position, in the linear accelerator beam, would reach the annual limit for Occupational Workers in a few seconds.)

\section{B. Peacekeeper Measurement Arrangement}

After laboratory physics proof-of-principle measurements conducted on a mockup at ANL, the laboratory gamma-ray transmission hodoscope system was transported to the Pacific Northwest Laboratory (PNL) for demonstration measurements on a Peacekeeper missile first stage. This stage included the casing and various flanges and other fittings, but did not have a nozzle, nozzle system components, or interstage hardware. The Peacekeeper first stage was used to prepare a system mockup arrangement that would simulate the radiation absorption characteristics of a rocket motor stage located inside a canister loaded inside a rail car. The Peacekeeper first stage had been test-fired prior to transfer to PNL, and thus it was necessary to provide an inert simulant for the solid fuel originally present inside the rocket motor. Dry sand, at a density of 1.8 grams/cc, was used. Table II lists the principal components of the mockup, as constructed at PNL for the measurements.

Table II

Components included with Peacekeeper first stage for the demonstration measurements

\begin{tabular}{lll}
\hline Item & \multicolumn{1}{c}{ Material } & Location \\
Fuel simulant & Dry sand & Inside empty first stage \\
Canister simulant & $\begin{array}{l}130 \mathrm{~mm} \\
\text { Fiberglas }\end{array}$ & $100 \mathrm{~mm}$ outside first stage \\
& $\begin{array}{l}2.5 \mathrm{~mm} \text { steel, } \\
\text { Rail car sides }\end{array}$ & $510 \mathrm{~mm}$ outside first stage \\
& $\begin{array}{l}130 \mathrm{~mm} \text { plastic } \\
\text { foam, and }\end{array}$ & \\
& $1.5 \mathrm{~mm}$ aluminum
\end{tabular}

The source-to-detector distance was about 4.8 meters, and the first stage was located in the middle. The hodoscope gamma-ray detectors were set up in two strings: a vertical string for diameter measurement, and a horizontal string for length (end) measurement. Detector spacing was $50 \mathrm{~mm}$ center-to-center in both strings. This corresponds to a pixel spacing of $25.4 \mathrm{~mm}$ for objects at the center of the radiography position. Finer resolution could be obtained by closer spacing and/or smaller detectors; however, this pixel size is adequate for the types of discrimination we considered. In any event, there is wide margin to permit smaller detectors to be used, should that be required. Cables from the detectors feed pulse output into amplifiers, and then into discriminators set to exclude counts outside the photopeaks for the 1.17 and $1.33 \mathrm{MeV}$ gamma-ray lines. Discriminator output pulses for each detector channel are recorded in the PC. One-minute counting times were used. The PC performs transmission, $T$, calculations, and provides both tabular and graphical data displays in near-real time after each measurement. Hard copy is provided by a printer.

We will present data for one pair of measurements: a vertical determination of the bottom diameter edge, and a horizontal determination of one end of the Peacekeeper. For the vertical measurement, the vertical detector string was aligned so that the path from the source to the bottom edge would pass between detecturs \#24 and \#25. (This path definition was determined independently by both PNL and ANL personnel.) For the horizontal measurement, the situation was somewhat different, because of the rounded end as shown in Fig 2. The end is a smooth curve, vertical in the (off limits) axial region, and tending to the horizontal at larger and larger radii, until the end makes a smooth transition to the cylindrical outside shell of the Peacekeeper. In the horizontal case, the horizontal detector string was set 
so that detector \#13 was in line with the sloping end edge at the string elevation. (This path also was determined independently by both PNL and AivL.) The horizontal string position should result in a high $\mathrm{T}$ reading for detector \#12, and a İow $\mathrm{T}$ for detector \#14, with detector \#13 yielding an intermediate value of $T$. This arrangement is illustrated in Fig. 3, which shows the detector assignment, and indicates schematically the relative counting rates for the detectors.

DIAMETER LOCATION
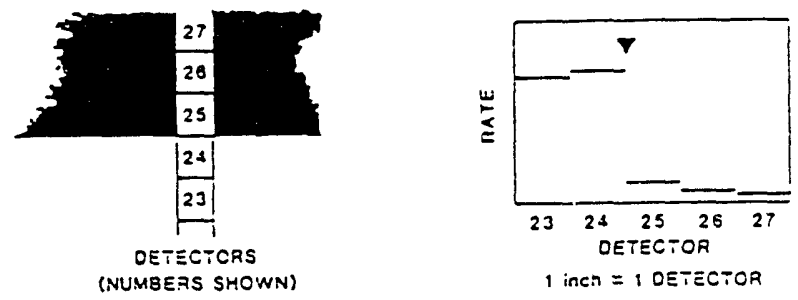

END LOCATION

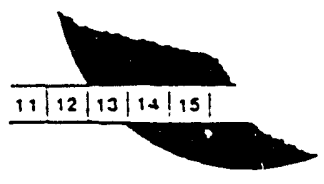

DETECTORS (NUMEEAS SHOWN)

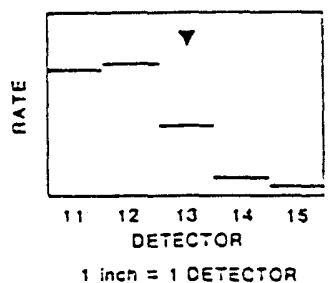

Fig. 3 Detector positioning and schematics of expected detector count rates

\section{Data}

Data taken with the full mockup, including fuel, canister, and rail car simulants are given in Figs 4. and 5. For convenience in presentation, the values of $T$ in each figure are normalized so that $\mathrm{T}$ just outside the rocket motor is approximately unity. The actual value of $\mathrm{T}$ just outside the rocket motor was about 0.5 in both cases. Figure 4 presents the actual values of $\mathrm{T}$ from the vertical, bottom diameter edge data. The relative values of $T$ for the detectors in Fig. 4 are in accord with the patterns presented in Fig. 3, as expected on the basis of the geometrical layout of the missile mockup arrangement and the vertical detector string. Similarly, Fig. 5 shows the $T$ values obtained from the horizontal, end edge measurement. These data also are in accord with the patterns given in Fig. 3. The effect of the rocket motor gamma-ray absorption is a reduction in : of about a factor of 5 , or more. The data in Figs 4 . and 5 . indicate that scattering is not a problem, and that the decision to omit detector shielding and collimation was correct.

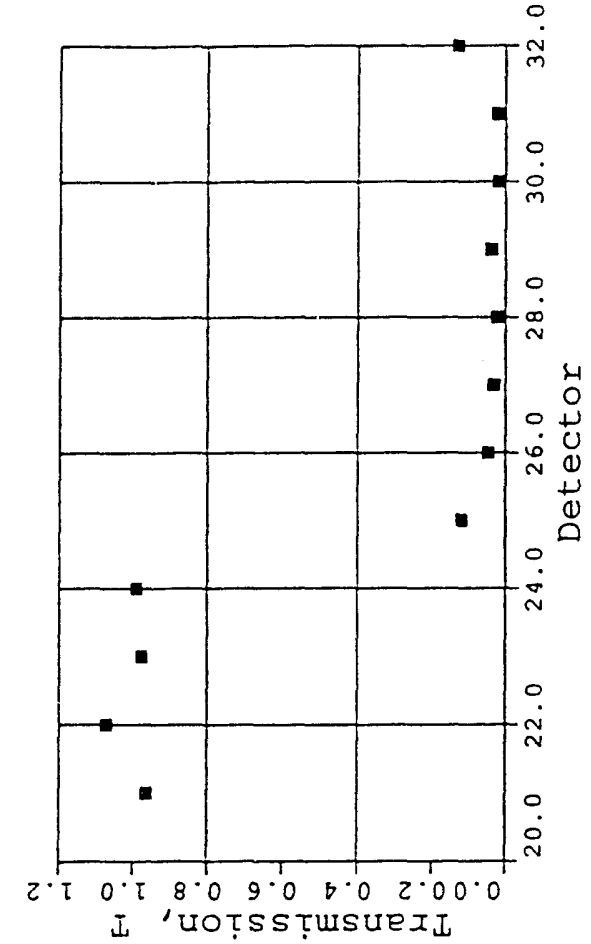

Fig. 4 Hodoscope vertical edge data showing bottom edge of Peacekeeper. Fuel, canister, and rail car simulants are in place

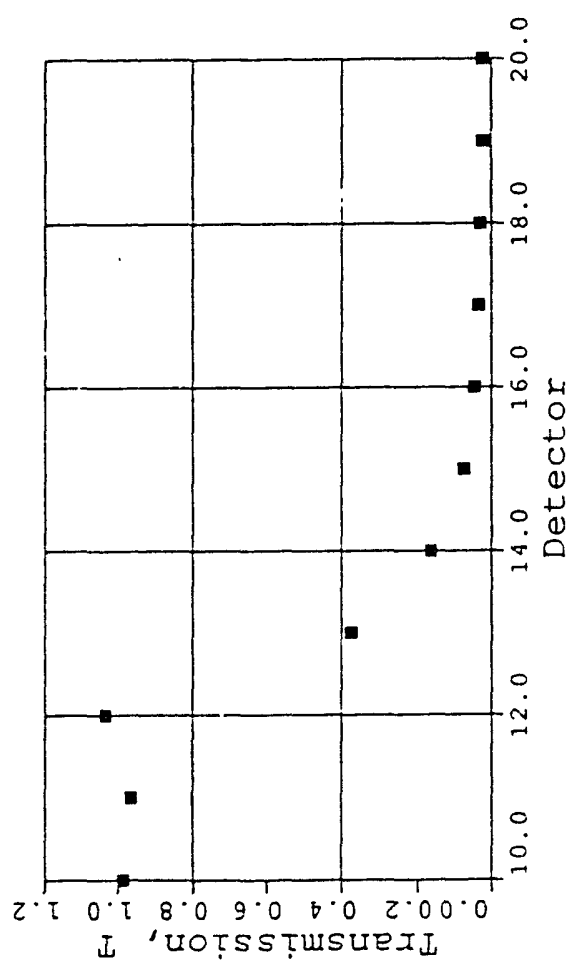

Fig. 5 Hodoscope horizontal edge data showing end edge of Peacekeeper. Fuel, canister, and rail car simulants are in place 


\section{DISCUSSION}

Data shown in Figs 4 and 5 showed a clearly discernable drop (of about a factor of 5) in detector transmission, $\mathrm{T}$, corresponding to the edge of the Peacekeeper stage. For the case in which one detector was aligned with the edge proper, that detector gave an intermediate value of $\mathrm{T}$ between the high and low values of the detectors on either side. These data were obtained with a relatively low-level radioactive source, and the measurement procedure is well within DOE ALARA radiation exposure guidelines.

The measurements confirmed the use of a gamma-ray transmission hodoscope to monitor the size of a rocket motor, enclosed within structure. In accord with previous physics mockup results, detector collimation and shielding were not needed. Adequate margin exists for the use of stronger sources or detectors of other sizes, should such measures be indicated for other applications.

Based on these results, procurement was initiated for a packaged demonstration prototype gamma-ray transmission hodoscope.

\section{ACKNOWLEDGEMENTS}

It is a pleasure to acknowledge the direction and encouragement of M. F. O'Connell, Project Manager for the Office of Arms Control, U.S. Department of Energy. We wish to acknowledge, with thanks, the fine cooperation and support extended by $\mathrm{N}$. Wogman of the Pacific Northwest Laboratory, and his staff, including: K. Abel, R. Campbell, J. Smart, and H. Undem. We also appreciate the continuing direction and support provided by Argonne Arms Control Project Manager A. Travelli and Technical Manager A. DeVolpi.

\section{REFERENCES}

[1] A. DeVolpi, C. L. Fink, G. E. Marsh, E. A. Rhodes, and G. S. Stanford, "Fast-neutron Hodoscope at TREAT: Methods for Quantitative Determination of Fuel Dispersal," Nucl. Tech, vol. 56, pp. 141-188, January 1982.

[2] K. Bohnel and H. Bluhm, "First Results of the CABRI Neutron Hodoscope," Proc. Int. Mtg. Fast Reactor Safety Technology. Seattle, WA, August 1979, pp. 2261-2269, American Nuclear Society.

[3] "Radiation Protection for Occupational Workers," U.S. Department of Energy Order 5480.11, December 1988.

\section{DISCLAIMER}

of work sponsored by an agency of the United States Government. Neither the United States Government nor any agency thereof, hor any of their employees, makes any warranty, express or implied, or assumes any legal apparatus, product, or bility for the accuracy, completeness, or usefulness of any information, apparatus, product, ence herein to any specific commervial product, process, or service by trade name, trademark, manufacturer, or otherwise dies not necessarily constitute or imply its endorsement, recommendation, or favoring by the United States Government or any agency thereof. The views and opinions of authors expressed herein do not necessarily state or reflect those of the United States Government or any agency thereof. 

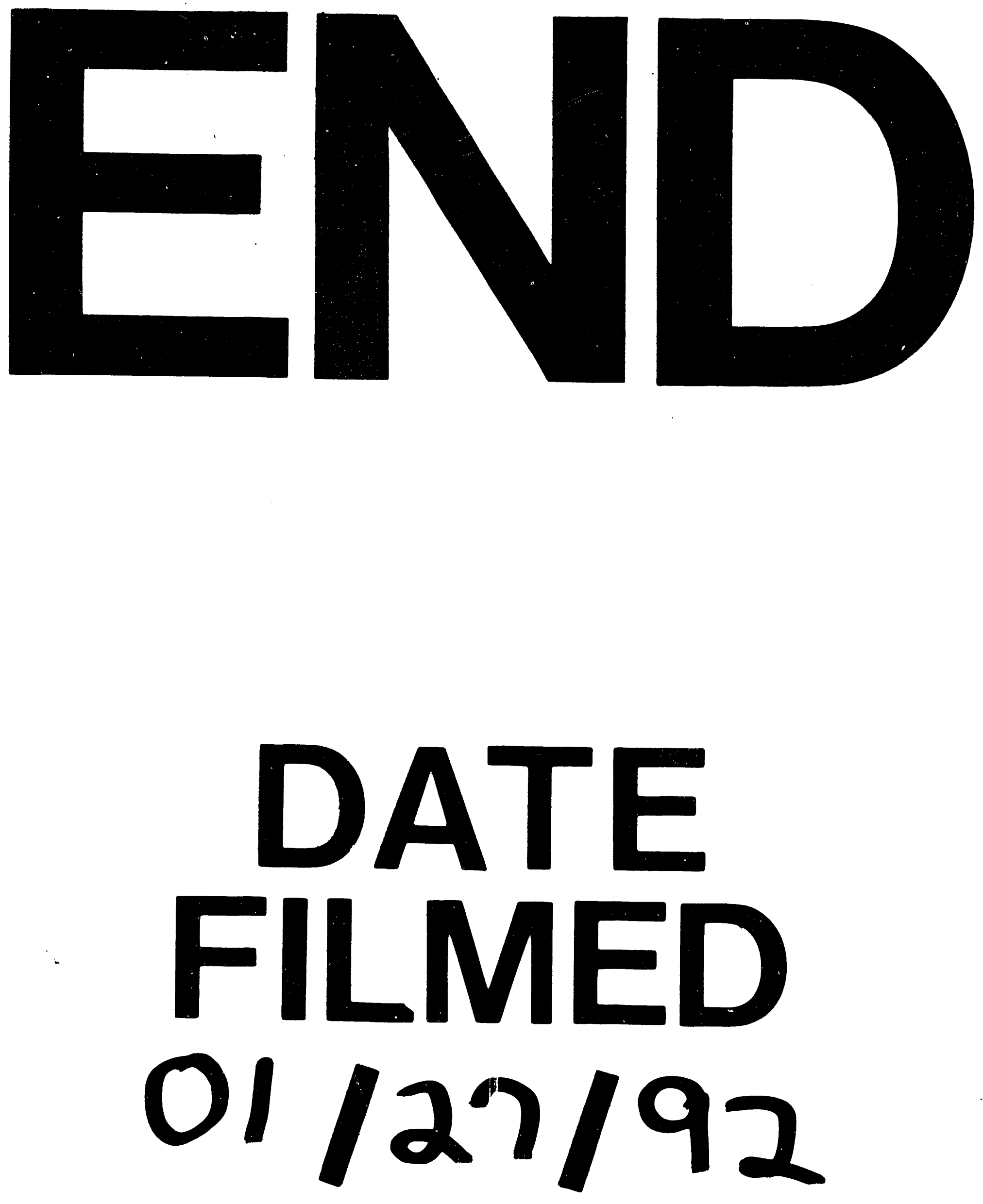
